\title{
Study of Aluminum Nitride Precipitation in Fe- 3\% Si Steel
}

\author{
Alcântara F.L. ${ }^{\text {a*, Barbosa R. }{ }^{\mathrm{b}} \text {, Cunha M.A. }}$ \\ ${ }^{\mathrm{a} A P E R A M}$ South America - Centro de Pesquisa, Praça $1^{\circ}$ de Maio, 9, \\ Centro, CEP 35180-018, Timóteo, MG, Brasil \\ ${ }^{\mathrm{b}}$ Departamento de Engenharia Metalúrgica e de Materiais, Universidade Federal de Minas Gerais - UFMG, \\ Av. Antônio Carlos, 6627, Pampulha, CEP 31270-901, Belo Horizonte, MG, Brasil \\ ${ }^{c}$ Departamento de Engenharia de Materiais e Engenharia Metalúrgica, Centro Universitário do Leste de Minas \\ Gerais - Unileste, Av. Tancredo Neves, 3500, Universitário, CEP 35170-056, Coronel Fabriciano, MG, Brasil
}

Received: November 22, 2012; Revised: February 13, 2013

\begin{abstract}
For good performance of electrical steels it is necessary a high magnetic induction and a low power loss when submitted to cyclic magnetization. A fine dispersion of precipitates is a key requirement in the manufacturing process of $\mathrm{Fe}-3 \% \mathrm{Si}$ grain oriented electrical steel. In the production of high permeability grain oriented steel precipitate particles of copper and manganese sulphides and aluminium nitride delay normal grain growth during primary recrystallization, causing preferential growth of grains with Goss orientation during secondary recrystallization. The sulphides precipitate during the hot rolling process. The aluminium nitride particles are formed during hot rolling and the hot band annealing process. In this work AlN precipitation during hot deformation of a high permeability grain oriented $3 \%$ Si steel is examined. In the study, transfer bar samples were submitted to controlled heating, compression and cooling treatments in order to simulate a reversible hot rolling finishing. The samples were analyzed using the transmission electron microscope (TEM) in order to identify the precipitates and characterize size distribution. Precipitate extraction by dissolution method and analyses by inductively coupled plasma optical emission spectrometry (ICP-OES) were used to quantify the precipitation. The results allowed to describe the precipitation kinetics by a precipitation-time-temperature (PTT) diagram for AlN formation during hot rolling.
\end{abstract}

Keywords: silicon steel, precipitation, aluminum nitride

\section{Introduction}

Electrical steels are used in electric power applications, typically as magnetic core materials for transformers, electric motors and generators. The sharp texture in grainoriented electrical steels is developed through secondary recrystallization. A basic metallurgical principle of secondary recrystallization is the inhibition of normal grain growth by the second phase particles present during primary recrystallization ${ }^{1}$.

It is well known that manganese sulfide (MnS), copper sulphide $(\mathrm{CuS})$ and aluminum nitride $(\mathrm{AlN})$ have been extensively used as grain growth "inhibitors" in electrical steels. The morphology, volume fraction and particle size distribution of precipitates have considerable importance in improving the final texture and, therefore, the magnetic properties of grain oriented steels. As large particles only exhibit a very small pinning effect on grain boundaries, it is important to know how to produce a fine dispersion of precipitates during hot rolling and first annealing. Thus, detailed and clear description of precipitation at high temperatures is of great interest ${ }^{2}$.

The most crucial point in manufacturing grain oriented silicon steel with high permeability, using AlN as the inherent inhibitor is to ensure that the AIN is finely

*e-mail: fabricio-luiz.alcantara@ aperam.com precipitated in the processes from steel making through hot-rolled sheet annealing.

The solubility product of AlN in silicon-steel, both in ferrite $^{4}$ and austenite ${ }^{3}$, have been described in literature and are expressed by Equations 1 and 2, respectively:

$$
\begin{aligned}
& \text { Ferrite } \Rightarrow \log [(\% A l)(\% N)]=-\frac{8296}{T}+1.69 \\
& \text { Austenite } \Rightarrow \log [(\% A l)(\% N)]=-\frac{7400}{T}+1.95
\end{aligned}
$$

Precipitation of AIN in silicon steel has been studied by Iwayama and Haratani ${ }^{5}$ and by $\mathrm{Oh}^{6}$. In this work the precipitates formed during hot deformation were characterized and the AIN precipitation kinetics was investigated. The results are discussed and compared to those obtained by Iwayama and Haratani ${ }^{5}$ and Oh et al. ${ }^{6}$.

\section{Experimental Procedure}

Transfer bar samples of Fe- 3\%Si Steel, which chemical composition is shown in Table 1, were used to prepare compression specimens with $90 \mathrm{~mm}$ in height and $10 \mathrm{~mm}$ in diameter. The specimens were initially heated to $1370{ }^{\circ} \mathrm{C}$ 
for 30 minutes and rapidly cooled in cold water. To prevent oxidation during heating and soaking the samples were sealed in quartz tubes under vacuum. Compression tests were carried out in a Gleeble 3500 machine using Strain Induced Crack Opening (SICO) Testing as schematically shown in Figure 1 . The tests were designed to study precipitation under conditions that simulate a reversible hot rolling finishing: the specimens were heated in the Gleeble machine to $1350^{\circ} \mathrm{C}$ for 5 minutes, cooled at $25^{\circ} \mathrm{C} / \mathrm{s}$ to the test temperature $\left(1200^{\circ} \mathrm{C}\right.$, $1100{ }^{\circ} \mathrm{C}, 1000^{\circ} \mathrm{C}$ and $900{ }^{\circ} \mathrm{C}$ ), held for 3 s for equalization before the first deformation pass; deformation of $40 \%$ was applied at a rate of $0.13 \mathrm{~s}^{-1}$, followed by soaking at the test temperature for different soaking times $(1,10,100,1000 \mathrm{~s})$ before the second deformation of $40 \%$ was applied, at the same deformation rate, followed by fast cooling in water.

In order to characterize the precipitates formed during the thermo-mechanical treatments, high resolution transmission electron microscopy observations were performed on carbon extraction replicas. Samples were prepared using standard techniques. To quantify the precipitation of AlN, the sample was dissolved with a solution of $\mathrm{I}_{2}$ in methanol. The solution was filtered and the residual, collected on a filter, was dissolved in a $\mathrm{HCl}$ solution and filtered again. The solution, added to $\mathrm{HNO}_{3}$ to destroy any organic trace, was analysed by inductively coupled plasma optical emission spectrometry (ICP-OES). The intensity of the emitted light from AlN was measured.

\section{Results and Discussion}

For all test conditions the precipitate particles were identified by EDS analysis and selected area diffraction.

Table 1. Chemical composition of the sample.

\begin{tabular}{cccccc}
\hline Element & Si & $\mathbf{C}$ & $\mathbf{N}$ & Al & $\mathbf{C u}$ \\
\hline$\%$ At & 3,028 & 0,069 & 0,0094 & 0,0216 & 0,0941 \\
\hline
\end{tabular}

For each kind of particle, sulphide, nitride or co-precipitate of sulphide and nitride, the particle size distribution was obtained from around 200 particles analysed per sample.

Figure 2 Shows the extraction replica micrograph and EDS spectrum of a sample deformed at $900{ }^{\circ} \mathrm{C}, 1000{ }^{\circ} \mathrm{C}$, $1100{ }^{\circ} \mathrm{C}$ and $1200{ }^{\circ} \mathrm{C}$ with 1000 s holding time between deformations. There are particles with spherical morphology and particles with spherical morphology associated with a cubic morphology. The particles with spherical morphology were identified as copper sulphide $\left(\mathrm{Cu}_{\mathrm{x}} \mathrm{S}\right)$ precipitates and the particles with spherical morphology associated with a cubic morphology were identified as $\mathrm{Cu}_{\mathrm{x}} \mathrm{S}+\mathrm{AlN}$ precipitates, where the spherical part corresponds to the $\mathrm{Cu}_{\mathrm{x}} \mathrm{S}$ and the cubic morphology to AlN. It is possible to observe also a difference in contrast between $\mathrm{Cu}_{\mathrm{x}} \mathrm{S}$ and $\mathrm{AlN}$ precipitates: $\mathrm{Cu}_{\mathrm{x}} \mathrm{S}$ shows darker contrast with the carbon layer whereas AlN contrast is weak. At $900{ }^{\circ} \mathrm{C}$ similar precipitates were observed even at $1 \mathrm{~s}$ soaking time between deformations, showing that under the test conditions of the present work incubation time for AlN precipitation at $900{ }^{\circ} \mathrm{C}$ is below 1s. The frequency of $\mathrm{Cu}_{\mathrm{x}} \mathrm{S}+\mathrm{AlN}$ particles increased with soaking time and the average particle size was $50 \mathrm{~nm}$.

Selected area diffraction has shown that the $\mathrm{Cu}_{\mathrm{x}} \mathrm{S}$ particles are hexagonal close-packed with lattice parameters $\mathrm{a}=0.3794 \mathrm{~nm}$ and $\mathrm{c}=1.6341 \mathrm{~nm}$; and that the AlN particles are face centred cubic crystals with lattice parameter $\mathrm{a}=0.3956 \mathrm{~nm}$, see Figure 3 .

At $1000{ }^{\circ} \mathrm{C}$ test temperature the spherical particles were identified as $\mathrm{Cu}_{\mathrm{x}} \mathrm{S}$ and $(\mathrm{Cu}, \mathrm{Mn}) \mathrm{S}$. The latter tended to increase in frequency with soaking time. The AlN precipitates appear associated with $\mathrm{Cu}_{\mathrm{x}} \mathrm{S}$, as described before, and with $(\mathrm{Cu}, \mathrm{Mn}) \mathrm{S}$. Nitride precipitates, associated with sulphides, were observed even at 1s soaking time, but the frequency of such precipitates increased with soaking, particularly above 100 s soaking. Average AlN co-precipitate particle size increased with soaking time, from $39 \mathrm{~nm}$ at $1 \mathrm{~s}$ soak to $73 \mathrm{~nm}$ at 1000 s soak.

Fumace

Gleeble

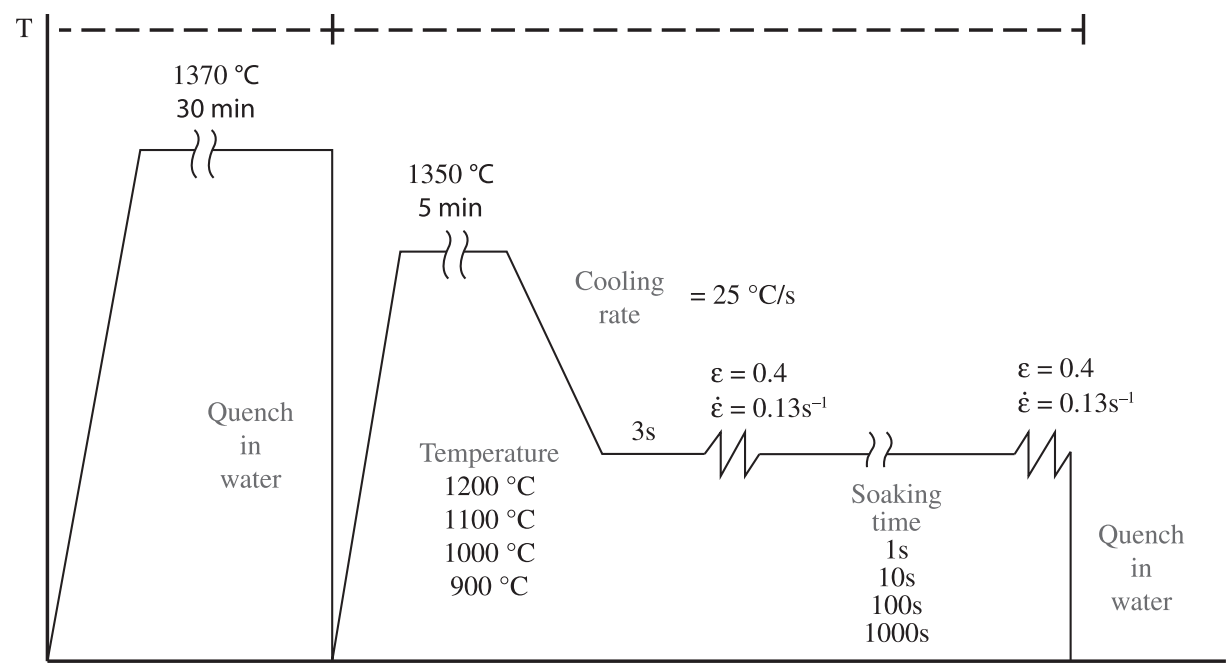

Figure 1. Annealing curve and thermomechanical treatment schedule for compression testing. 


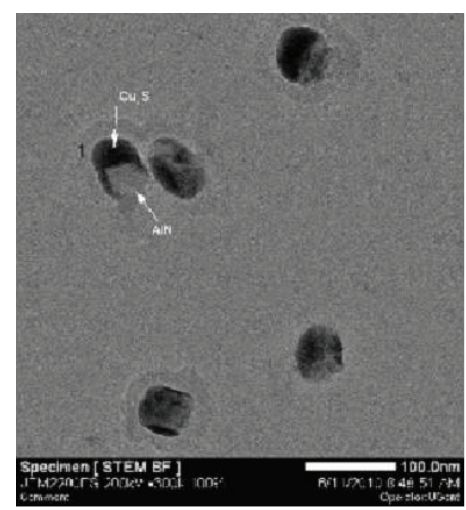

(a)

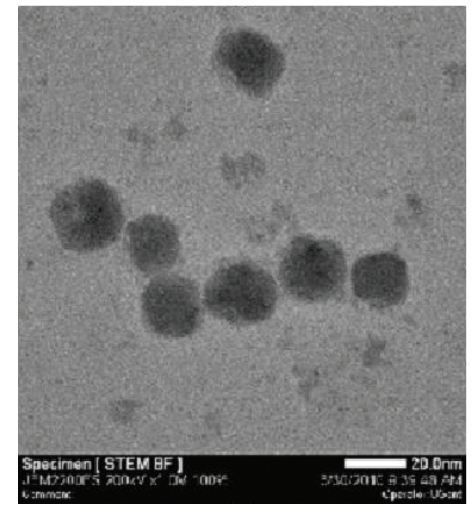

(c)

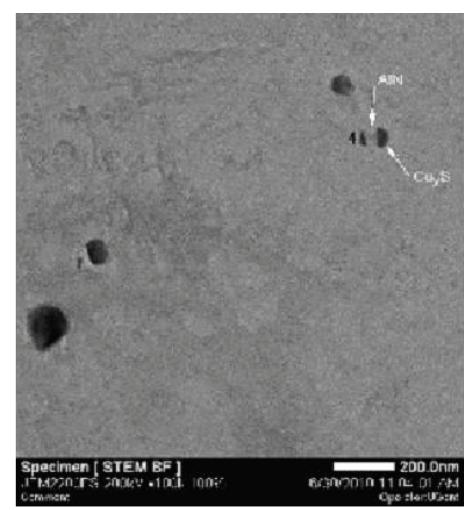

(b)

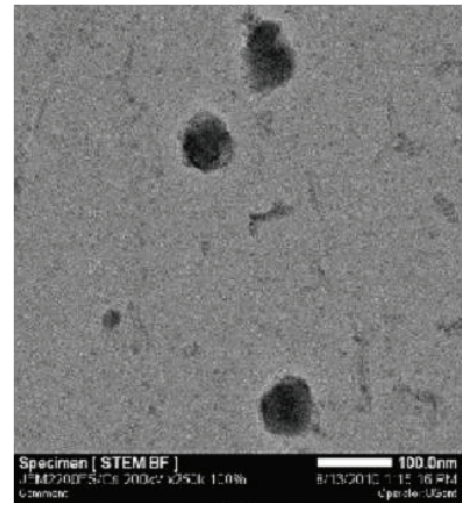

(d)

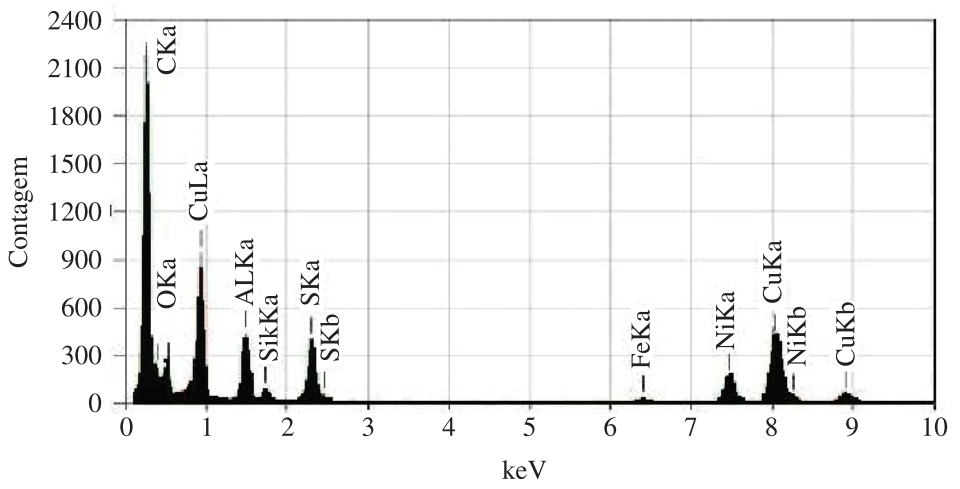

(e)

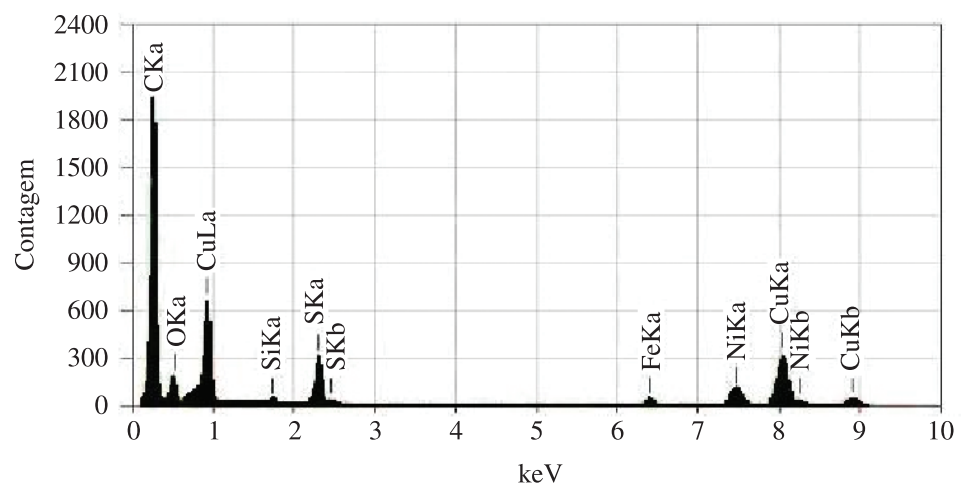

(f)

Figure 2. TEM carbon extraction replica micrograph showing precipitation of $\mathrm{Cu}_{\mathrm{x}} \mathrm{S}+\mathrm{AlN}$ and $\mathrm{Cu}_{\mathrm{x}} \mathrm{S}$ at $900^{\circ} \mathrm{C}(\mathrm{a}), 1000^{\circ} \mathrm{C}(\mathrm{b}), 1100^{\circ} \mathrm{C}$ (c) and $1200^{\circ} \mathrm{C}(\mathrm{d})$, and EDS spectrum of the $\mathrm{Cu}_{\mathrm{x}} \mathrm{S}+\mathrm{AlN}$ particles (e) and $\mathrm{Cu}_{\mathrm{x}} \mathrm{S}$ (f) with $1000 \mathrm{~s}$ holding time between deformations. 


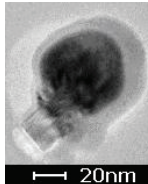

(a)

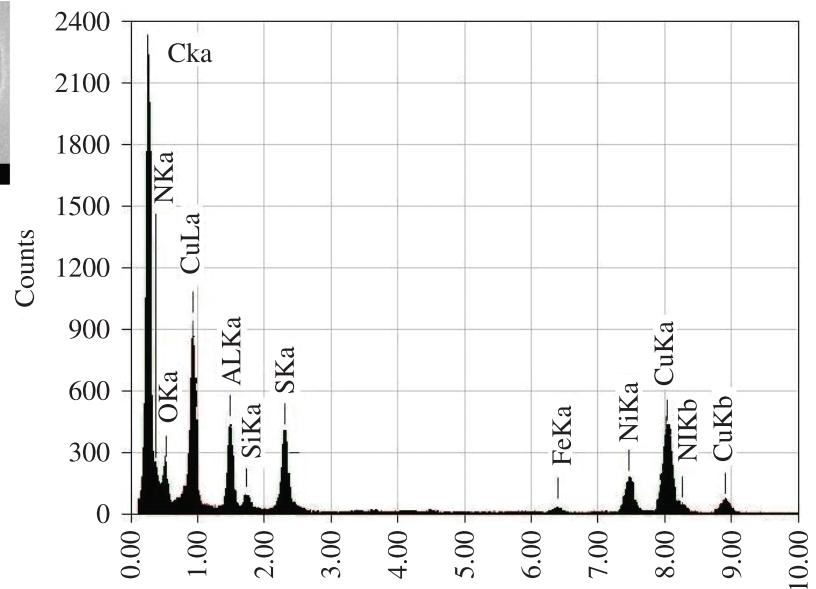

$\mathrm{keV}$

(b)

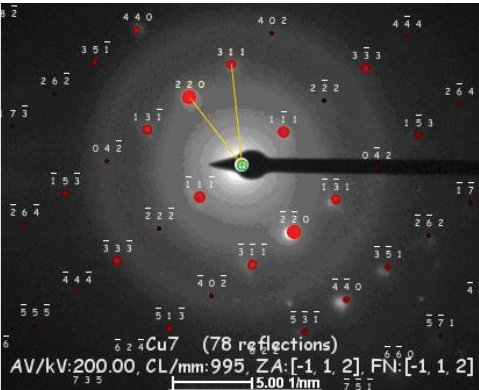

(c)

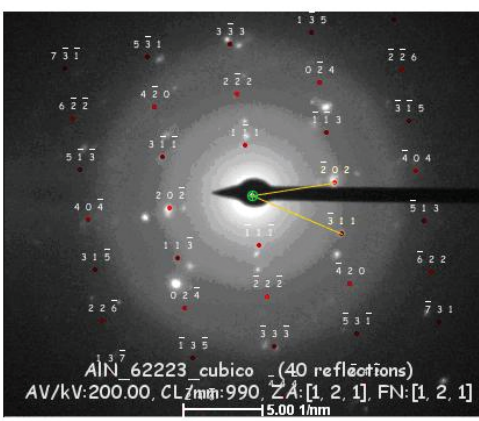

(d)

Figure 3. Micrograph of $\mathrm{Cu}_{\mathrm{x}} \mathrm{S}+\mathrm{AlN}$ precipitate (a), EDS spectrum (b) and diffraction pattern ((c) and (d)) for the sample performed at $900^{\circ} \mathrm{C}$.

By selected area diffraction two kinds of copper sulphides were identified: Hexagonal close-packed as described above, and face centred cubic with lattice parameter $\mathrm{a}=0.5582 \mathrm{~nm}$. Based on average EDS results the face centred cubic particles could be described as $\mathrm{Cu}_{1.8} \mathrm{~S}$. The $(\mathrm{Cu}, \mathrm{Mn}) \mathrm{S}$ precipitates also showed face centred cubic structure with lattice parameter $\mathrm{a}=0.559 \mathrm{~nm}$.

For the test temperatures of $1100{ }^{\circ} \mathrm{C}$ and $1200{ }^{\circ} \mathrm{C}$ the precipitate particles were predominantly sulphides, with increasing frequency of $(\mathrm{Cu}, \mathrm{Mn}) \mathrm{S}$ particles with increasing temperature and soaking time.

On the aluminum nitride formation, $\mathrm{Al}+\mathrm{N}=\mathrm{AlN}$, the stoichiometry relation between nitrogen $\left(\mathrm{N}_{\mathrm{p}}\right)$ and aluminum $\left(\mathrm{Al}_{\mathrm{p}}\right)$ contents on the precipitate formation is given by Equation 3:

$A l_{p}=\frac{26.98}{14.01} N_{p}$

The contents of $\mathrm{Al}$ and $\mathrm{N}$ dissolved in each phase, in a specific temperature, were obtained by the difference related to $\mathrm{Al}$ and $\mathrm{N}$ totals in the steel, $\mathrm{Al}_{\mathrm{T}}$ and $\mathrm{N}_{\mathrm{T}}$, respectively Equation 4 and Equation 5:

$A l_{d}=A l_{T}-A l_{P}$

$N_{d}=N_{T}-N_{P}$

According to the Equation 1 and 2, the solubility product of aluminum nitride in each phase is given by Equation 6:

$L_{A I N}=10\left(-\frac{A}{T}+B\right)$
That is, $A l_{d} N_{d}=L_{A l N}$, which enables to obtain the following Equation 7 to calculate the precipitated nitrogen content in a phase, according to temperature.

$$
\frac{26.98}{14.01} N_{P}^{2}-\left(A l_{T}+\frac{26.98}{14.01} N_{T}\right) N_{P}-10^{\left(-\frac{A}{T}+B\right)}+A l_{T} N_{T}=0
$$

The value of $\mathrm{N}_{\mathrm{d}}$ obtained represents the solubility limit on the considerer phase. With the austenite and ferrite fractions given by Thermo-Calc and the expressions of aluminum nitride solubility product on the austenite and ferrite, Equation 1 and Equation 2, it is possible to calculate the contents of $\mathrm{N}$ dissolved on the steel according to the temperature $\left(N_{d}^{\text {steel }}\right)$ by the Equation 8:

$$
N_{d}^{\text {steel }}=N_{d}^{\alpha} f_{\alpha}+N_{d}^{\gamma} f_{y}
$$

Where $\mathrm{f}_{\alpha}$ and $\mathrm{f}_{\gamma}$ are the equilibrium fraction of ferrite and austenite and, $N_{d}^{\alpha}$ and $N_{d}^{\gamma}$ are the limits of solubility on the respective phases. As the stoichiometry relation on the precipitate is kept, you can obtain the values of $\mathrm{N}$ and $\mathrm{Al}$ precipitated on the steel according to temperature.

The amount of Al as precipitate, measured by dissolution and ICP-OES analysis, for the different test temperatures and soaking times, is shown in Figure 4. To estimate the fraction of precipitation for the different test temperatures and soaking times, in relation to the equilibrium, it was assumed that $\mathrm{Al}$ in the precipitates is present only in AlN particles. The amount of $\mathrm{Al}$ as $\mathrm{AlN}$ in the equilibrium was calculated from Equations 1 and 2 and of the equilibrium percentages of ferrite and austenite at the different temperatures. The equilibrium percentage of 
$\mathrm{Al}$ as AlN precipitate, as a function of temperature, is also shown in Figure 4. For high test temperatures and long soaking times the values of $\mathrm{Al}$ as $\mathrm{AlN}$ tend to approach the calculated equilibrium values. According to Figure 4, AlN precipitation starts at $1124{ }^{\circ} \mathrm{C}$.

Figure 5 shows the PPT curve for aluminum nitride obtained in this work, showing precipitation start and 50\% precipitation, compared with start precipitation obtained by Haratani ${ }^{5}$ and by $\mathrm{Oh}^{6}$. In order to elaborate this curve it was calculated the ratio between the values of $\mathrm{Al}$ as $\mathrm{AlN}$ precipitate found by ICP-OES analyses and the values of Alp calculated as described earlier. The shortest precipitation time in Haratani's work was $14 \mathrm{~s}$ at $1150{ }^{\circ} \mathrm{C}$; in Oh's work, $95 \mathrm{~s}$ at $1000{ }^{\circ} \mathrm{C}$; in the present work, less than $1 \mathrm{~s}$ at a temperature lower than $900^{\circ} \mathrm{C}$.

For a temperature of $900{ }^{\circ} \mathrm{C}$, the high dislocation density produced with the initial deformation and the lower recuperation rate propitiates a higher nucleation rate, hence the higher fraction precipitated for permanence time of $1 \mathrm{~s}$ and $10 \mathrm{~s}$. As the growth rate of particles is lower than $1000{ }^{\circ} \mathrm{C}$, because of the lower diffusion coefficient, and the volumetric fraction of precipitate on the equilibrium is higher $\left(900^{\circ} \mathrm{C}\right)$, for long permanency time the percentage

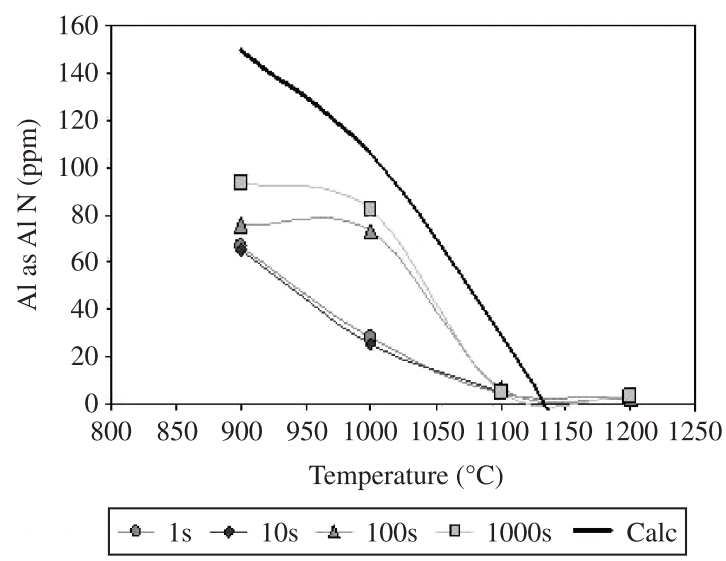

Figure 4. The content of $\mathrm{Al}$ as $\mathrm{AlN}$ precipitate for the different test temperatures and soaking times. precipitated is lower than $1000{ }^{\circ} \mathrm{C}$. Also, for a long time of permanence at $900{ }^{\circ} \mathrm{C}$, the recuperation will lead to a reduction of dislocation density, affecting on nucleation rates and growth.

The differences observed between the present work and the works of Haratani ${ }^{5}$ and $\mathrm{Oh}^{6}$ can be explained based on the chemical composition of silicon steels used in each case, the use of deformation to induce precipitation and the deformation rates applied in the experiments.

Precipitation temperature is determined by solubility product and the relative amounts of ferrite and austenite in the structure. Although the steel used in the present experiment had higher solubility product than in references ${ }^{5,6}$, it had higher carbon content and so higher percentage of austenite. The equilibrium temperatures for start precipitation, calculated based on Equations 1 and 2 and the equilibrium fractions of ferrite and austenite, as explained above, were $1288{ }^{\circ} \mathrm{C}$ and $18.65 \%$, obtained by Haratani and $1160{ }^{\circ} \mathrm{C}$ and $27.50 \%$, obtained by $\mathrm{Oh}$.

The time for precipitation start was studied by Dutta and Sellars ${ }^{7}$ and depend on supersaturation, activation energy, deformation and deformation rate. The use of high deformation rate in the present experiment explains the short incubation time compared with the works of Haratani and Oh. In Haratani's experiments no deformation was applied. In Oh's work two deformation rates were used, $3.4 \times 10^{-5} \mathrm{~s}^{-1}$ e $1.1 \times 10^{-1} \mathrm{~s}^{-1}$, which are lower than the deformation rate used in the present work $\left(0.13 \mathrm{~s}^{-1}\right)$. Based on the work of Dutta and Sellars ${ }^{7}$, the precipitation start time is proportional to the inverse square root of the deformation rate:

$$
t_{p s} \propto \dot{\varepsilon}^{-0.5}
$$

In ferrite the recovery rate is higher than in austenite, due to the higher stacking fault energy, and so the start precipitation time can be expressed by ${ }^{6}$ :

$$
t_{p s} \propto \dot{\varepsilon}^{-0.3}
$$

In Figure 6 the precipitation start time obtained in this work is compared with data from Oh's work, with good agreement with the expression above.

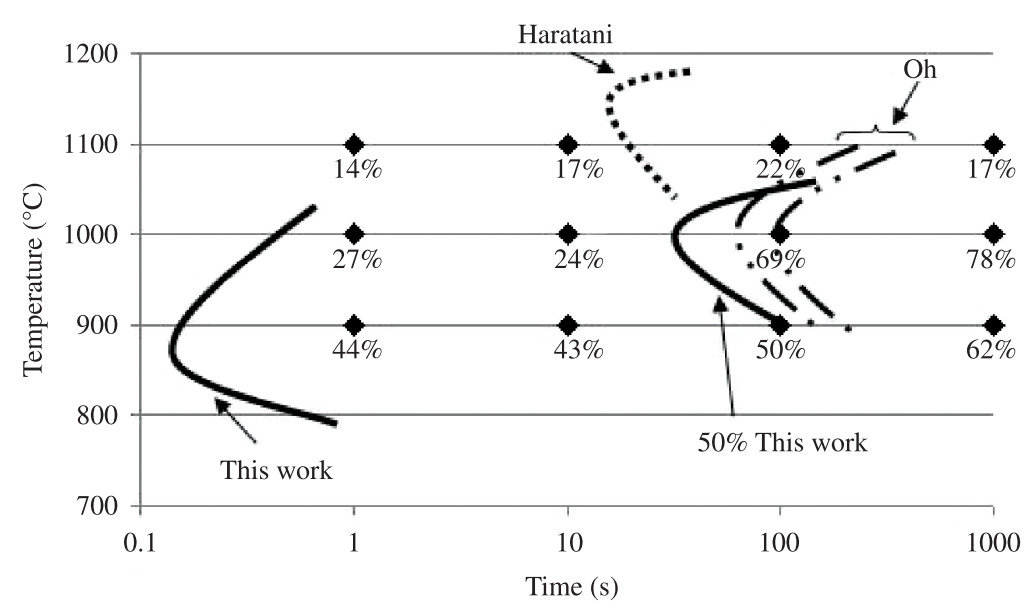

Figure 5. PPT curves for $\mathrm{AlN}$ in 3\% Si-Fe obtained from this work. 
The nitride particles observed in the present work were always associated with sulphide particles, particularly $\mathrm{Cu}_{\mathrm{x}} \mathrm{S}$, that tended to precipitate over the AIN particle. A more

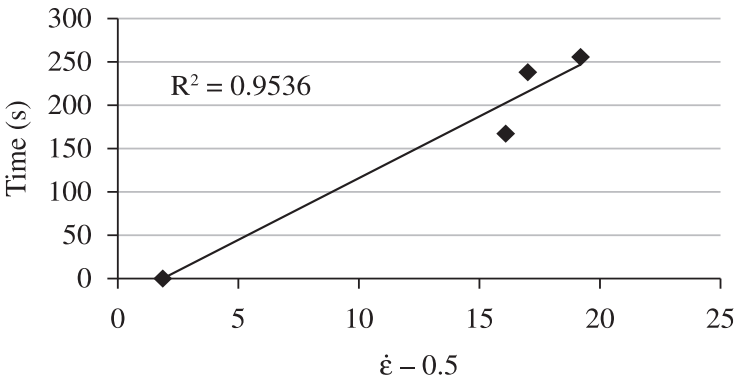

Figure 6. Effect of deformation rate on precipitation start time.

\section{References}

1. Cheng LM. Dissolution, Coarsening and Growth of Aluminum Nitride in Low Carbon Steels - Distribution. [Thesis]. Vancouver: University of British Columbia; 1999.

2. Sun WP. Measurement and Analysis of MnS Precipitation in Electrical Steel. [Thesis]. Montreal: Faculty of Graduate Studies and Research; 1991.

3. Darken LS, Smith RP and Filer EW. Solubility of Gaseous Nitrogen in $\gamma$ Iron and the Effect of Alloying Constituents - Aluminium Nitride Precipitation. Transactions of the American Institute of Mining and Metallurgical Engineers. 1951; 191:1174-79. detailed description of sulphide precipitation kinetics will be the subject of another paper.

\section{Summary}

- The PTT diagrams determined by the present compression test for AIN precipitation in the dualphase 3\% Si electrical steel are generally C-shaped, with the nose located under at $900{ }^{\circ} \mathrm{C}$, for time lower than 1 second, and its precipitation doesn't finish before 1000 seconds of test;

- The precipitation start curve obtained here is moved to shorter times because of the chemical composition of silicon steels used and the use of deformation to induce precipitation and the deformation rate applied in the experiments;

- CuS precipitate has a hexagonal close-packed structure and AlN has a face centered cubic structure.

4. SawamuraHandMoriT.Thermodynamic investigation of nonmetallic inclusions in steel (I). Tetsu to Hagane. 1955; 41(10):1082-90.

5. Iwayama $\mathrm{K}$ and Haratani T. The Dissolution and Precipitation Behavior of AlN and MnS in Grain Oriented 3\% Silicon Steel with High Permeability. Journal of Magnetism and Magnetic Materials. 1980; 19:15-17. http://dx.doi.org/10.1016/03048853(80)90540-5

6. Oh JH, Cho SH and Jonas JJ. AlN Precipitation in Dual-phase 3\% Si Electrical Steels. ISIJ International. 2001; 41:484-491. http://dx.doi.org/10.2355/isijinternational.41.484

7. Dutta B, Valdes E and Sellars CM. Mechanism and Kinetics Strain Induced Precipitation of $\mathrm{Nb}(\mathrm{C}, \mathrm{N})$ in Austenite. Acta Metallurgica et Materialia. 1992; 40:653-662. http://dx.doi. org/10.1016/0956-7151(92)90006-Z 